\title{
A POESIA DE MALLARMÉ ENCONTRA A PINTURA DE MANET
}

Caroline Pessoa Micaelia ${ }^{1}$

RESUMO: Dentre os trabalhos críticos que o jovem Mallarmé dedicou à pintura, "The Impressionists and Édouard Manet" (1876) talvez seja o mais importante, mesmo sendo provavelmente o mais desconhecido. Isso se explica uma vez que seu manuscrito francês tem paradeiro desconhecido, sendo nossa única fonte, atualmente, uma tradução inglesa. Trata-se, no entanto, de um trabalho que marca a passagem ao tipo de escrita e análise que Mallarmé passaria a empreender em sua obra tardia. Nesse texto, o poeta comenta a prática dos pintores impressionistas, sobretudo de Manet, estabelecendo uma analogia entre os caminhos da pintura e os da poesia em fins do século XIX francês. Este artigo busca explorar a abordagem analógica de Mallarmé em "The Impressionists", valendo-se das reflexões que o poeta elabora sobre Manet e sobre o impressionismo para investigar como esse pensamento encontra par em seus próprios trabalhos. Partindo das quatro linhas de força que, segundo Bertrand Marchal (2011), Mallarmé observaria nos trabalhos desses artistas (ar livre, simplificação, perspectiva e descondicionamento do olhar), assim como de textos mallarmeanos tão diversos quanto La Musique et les Lettres (1895) e "Don du poëme" (1866) - mas sem perder de vista a historicidade de ambos -, o intuito aqui consiste em mostrar como as trajetórias da poesia e da pintura se tocam, naquele fim de século, através de alguns pontos de encontro entre a obra de Mallarmé e a de Manet.

PALAVRAS-CHAVE: "The Impressionists and Édouard Manet"; Stéphane Mallarmé; Édouard Manet; poesia; pintura.

\section{MALLARMÉ'S POETRY JOINS MANET'S PAINTING}

ABSTRACT: Within the scope of Mallarmés early critical works on painting, "The Impressionists and Édouard Manet" (1876) is probably his most important piece, in spite of being as well his less known. Such contradiction is justified by an absence of its French manuscript, thereby leaving an English translation as our only source. This particular work marks, nevertheless, the passage to the sort of writing and analysis Mallarmé would produce in his late days. In it, he comments the Impressionists' practice, and Manet's above all; he establishes, moreover, an analogy between French poetry and painting in late nineteenth century art. The present study seeks to explore Mallarmé's analogical approach in "The Impressionists". It gives a closer look to the poet's thoughts on Manet and the Impressionists in order to investigate how his ideas about painting find a match in his own poetical works. In 2011, Bertrand Marchal pointed out four guidelines (open air, simplification, perspective, and deconditioning of the look) through which Mallarmé would read those painters' activity in "The Impressionists". From this point of departure, our goal here is to confront his analysis with some aspects of his own poetics. To do so, we will come across texts as distinctive as La Musique et les Lettres (1895) and "Don du poëme" (1866), without losing sight of these works' historicity. The attempt of this paper is to show where poetry joins painting in that fin de siécle by comparing Mallarmé's and Manet's ouvres.

KEYWORDS: "The Impressionists and Édouard Manet"; Stéphane Mallarmé; Édouard Manet; poetry; painting.

\footnotetext{
${ }^{1}$ Doutoranda, Universidade de São Paulo, carolinemicaelia@hotmail.com.
} 


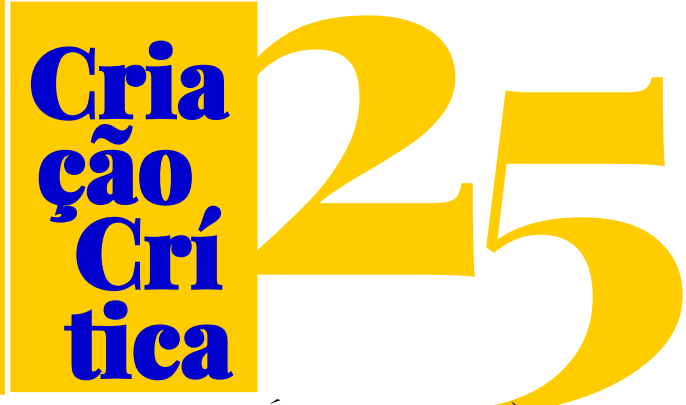

Manet apenas "um último desafio romântico" (DRAGUET in MALLARMÉ, 1998, p. 45), para Mallarmé, Manet é símbolo maior de modernidade em pintura e responsável pela "constituição de uma frente 'impressionista' que revolucionará a estética, fundando-se sobre uma nova consciência" ${ }^{8}$ (DRAGUET in MALLARMÉ, 1998, p. 45).

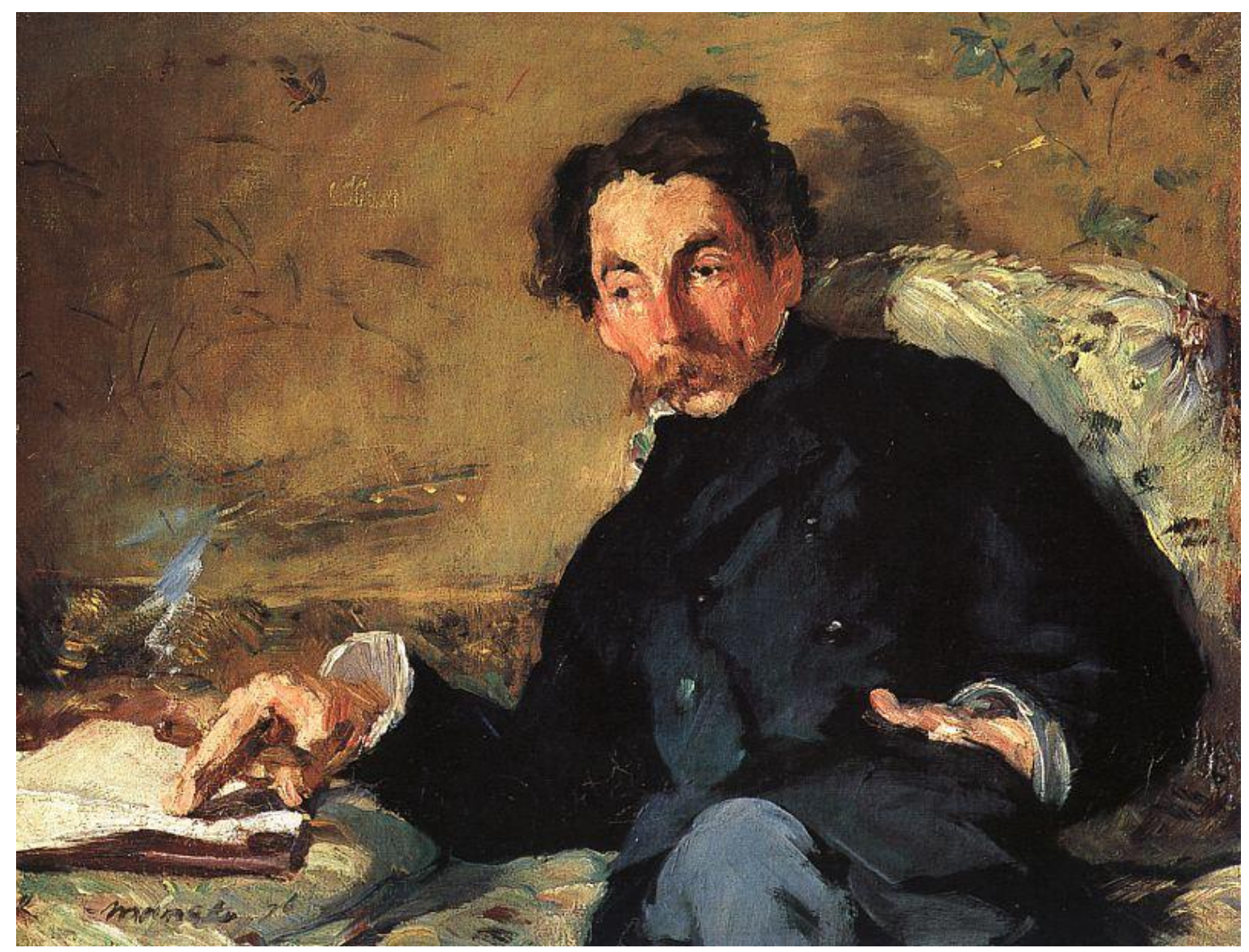

Figura 1 - Portrait de Mallarmé, 1876, óleo sobre tela, 27 x 36 cm, Musée d'Orsay, Paris

Tal, como procurarei explorar no presente artigo, é o espírito reinante nesse "grande estudo de 1876", cujo título, "The Impressionists and Édouard Manet", ressalta o duplo interesse de Mallarmé no que diz respeito à pintura.

Com efeito, a origem desse texto está antes numa longa reflexão sobre a atividade de Manet e dos outros pintores impressionistas - a nova forma de pintar que eles preconizam, bem como suas consequências para o futuro das artes - do que na energia liberada pela amizade entre poeta e

\footnotetext{
8 "un ultime défi romantique, Mallarmé souligne la constitution d'un front 'impressionniste' qui révolutionnera l'esthétique en se fondant sur une nouvelle conscience."

9 "The Impressionists and Édouard Manet" tem seu título em inglês por se tratar, efetivamente, de uma tradução. O tex to possui uma história curiosa: em 1876, o periódico inglês The Art Monthly Review pede a Mallarmé que escreva um artigo sobre o então novo movimento de pintura - o impressionismo. Mallarmé o escreve em francês, envia-o à revista, onde o editor George T. Robinson o traduz e publica em inglês. O texto não chega a ser publicado em terras francesas no século XIX e o manuscrito francês de Mallarmé tem, atualmente, paradeiro desconhecido. Assim sendo, não parece haver saída a não ser considerar o texto em inglês como original. Para maiores desdobramentos a respeito dessa história e dos problemas que ela apresenta, ver AUTOR, 2019.
} 


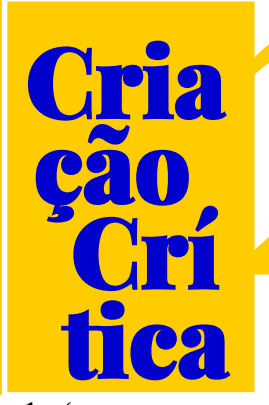

pintor. "O caso Mallarmé e o caso Manet", afirma Durand (1998, p. 14), "ultrapassam suas personalidades individuais, indicando mais amplamente duas situações semelhantes nos respectivos universos sociais" ${ }^{\prime 10}$, de modo que o percurso do poeta, para muito além de prestigiar a obra do amigo, aponta para o estabelecimento de uma analogia entre as mudanças pictóricas protagonizadas pelos impressionistas e aquelas pelas quais passava a poesia no final do XIX, com quebra do metro, a ascensão da prosa $^{11}$ e a desvalorização do modelo retórico clássico, até então em vigor.

Em alguns momentos do texto, essa analogia se mostra clara. É o que acontece, por exemplo, com o uso da palavra crise para designar as mudanças pelas quais passava, então, a literatura. Esse conceito, fundamental para o conjunto dos escritos de Mallarmé, se manifesta em contextos distintos entre os anos 1870 e os anos 1890, e está essencialmente vinculado à noção de crítica. Ele responde a um olhar e a um projeto críticos sobre os quais, a partir de "The Impressionists" - primeira ocorrência do termo na obra do poeta -, seria fundada toda a obra mallarmeana em prosa. Ora, no texto sobre os impressionistas, é questão de colocar deliberadamente em relação essa crise - essa crítica - da literatura e a crise na qual os pintores do movimento inserem as concepções tradicionais de pintura.

Este trabalho procura realçar esse ímpeto analógico de Mallarmé em "The Impressionists"12, lançando mão das reflexões que o poeta constrói sobre Manet e sobre o impressionismo para investigar em que medida tais reflexões encontram par em seus próprios textos poéticos. Para tanto, a maior parte dos trabalhos mallarmeanos utilizados aqui - fora o próprio "The Impressionists", que está na origem deste estudo - são tardios, datando dos anos 1890. Isso se explica porque, no artigo de 1976 surgem algumas das questões - como a da crise, por exemplo - que seriam destrinchadas nas últimas prosas de Mallarmé, com destaque para La Musique et les Lettres (1895). Não obstante, com o intuito de mostrar o modo como algumas dessas reflexões aparecem, de outra maneira, nos textos de juventude, um dos exemplos utilizados é um quarteto de "Don du poëme" (1866).

De acordo com Marchal (2011, p. 338), em artigo sobre a atividade de Mallarmé como crítico de arte, "The Impressionists" coloca em cena o poeta lendo a prática impressionista através de quatro linhas de força, 1) o ar livre; 2) a simplificação; 3) a perspectiva; e 4) o descondicionamento do olhar. Essas diretrizes, como procurarei mostrar, parecem estar em inequívoca relação de analogia com seu projeto poético; elas serão objetos de estudo nas próximas páginas.

Mas antes disso, parece importante relembrar alguns dos pilares que apoiavam a pintura da tradição, e só então analisar o motivo pelo qual tais linhas de força se contrapõem a esses pilares.

\footnotetext{
10 "Le cas Mallarmé et le cas Manet dépassent leurs personnalités individuelles, indiquent plus largement deux situations semblables dans leurs univers sociaux respectifs."

${ }^{11}$ Para um maior aprofundamento a respeito desses dois primeiros temas, ver AUTOR, 2016.

${ }^{12}$ Não se trata, portanto, de analisar o texto em sua integralidade.
} 
Até o século XIX, quando um aluno ingressava na Academia de Belas Artes, ele tinha, num primeiro momento, aulas de desenho, geometria, perspectiva, anatomia, mitologia, religião e história da França. Em seguida, esse estudante aprendia a parte prática do métier em ateliês de artistas já consagrados. Finalmente, uma última etapa dessa formação consistia em ir ao Louvre para copiar as telas dos grandes mestres do passado.

A trajetória é relevante aqui pois sublinha alguns dos aspectos responsáveis por reger as práticas artísticas tradicionais. Voltemo-nos para eles.

Antes de mais nada, era preciso respeitar uma hierarquia de gêneros pictóricos, pois, como em literatura, os diferentes gêneros de pintura possuíam valor distinto uns dos outros - o quadro de grandes dimensões correspondia a um quadro de gênero elevado, ao passo que os quadros de pequenas dimensões eram utilizados na prática de gêneros menores. Nessa lógica, falar em tela grande, à época, era falar não apenas no tamanho das telas, mas também em assuntos elevados, os quais, nesse caso, poderiam ser mitológicos, bíblicos ou históricos. Do ponto de vista do tema, o retrato de pé, embora não fosse tão prestigioso quanto esses últimos três, era também considerado um grande gênero.

Em seguida, tinha-se o que se nomeava, justamente, pintura de gênero, à qual competia a representação das cenas do cotidiano, e, abaixo da pintura de gênero, encontrava-se a paisagem, realizada até então num pequeno formato. O gênero mais baixo era a natureza morta, última instância de uma hierarquia que determinava, consequentemente, os grandes pintores como sendo aqueles que se voltavam para a Bíblia, a mitologia ou a história - assuntos que, da maneira como se compreendia à época, favoreciam a primazia da idealização. Os pintores de retrato, os pintores de gênero, os paisagistas e, por fim, os que retratavam a natureza morta seguiam, nessa ordem, o esquema hierárquico.

A ligação entre pintura e literatura estava também no fato de a arte da tradição ser movida por convenções, dentre as quais caberia falar num idealismo quanto à ideia de beleza; uma visão ideal do belo, concebida a partir da estatuária antiga. Assim, um pintor da tradição não se preocupa em pintar a realidade, na medida em que o real se opõe ao ideal. Num sentido mais amplo, a cultura adquirida se sobrepunha à observação da realidade ou da natureza, de tal modo que a pintura era tratada como uma arte ligada à memória, conforme defende Baudelaire (1954 [1885], p. 895), em "L'art mnémonique": "Na realidade, todos os desenhistas bons e verdadeiros desenham a partir da imagem escrita no cérebro, e não a partir da natureza." ${ }^{13}$ A ideia, aqui, é a de que era preciso fazer melhor do que a natureza. Nessa lógica, seguindo a fórmula de Horácio (2013 [14-10 a. C], p. 40-41), ut pictura poesis (do latim, "a poesia é como a pintura"), até o século XIX, a pintura, como a literatura, atendiam a uma estrutura retórica clássica, ou seja, os observadores reconheciam o código, e o quadro, construído à luz daquele código, cumpria uma função, produzia um efeito.

\footnotetext{
13 "En fait, tous les bons et vrais dessinateurs dessinent d'après l'image écrite dans leur cerveau, et non d'après la nature."
} 


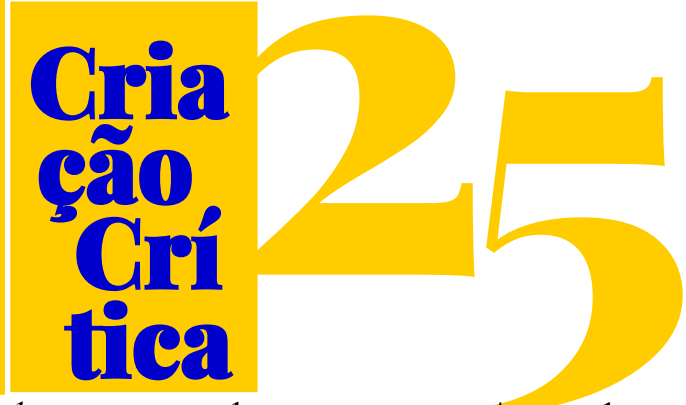

Arte de convenção não apenas, mas igualmente arte de construção: havia uma exigência de que o pintor dominasse regras matemáticas de perspectiva, pensada nos termos de Leon Battista Alberti (1404-1472), como define Marchal (2011, p. 335) - o quadro era composto a partir de pequenos retângulos, pintados um a um. Era questão, segundo Mariko Shigemitsu (2007, p. 28), de uma noção de perspectiva fundamentalmente artificial, calculada, que "organiza[va] os objetos como se eles fossem fixos e estáticos, talvez com a intenção de dar a impressão de um tempo eterno e estável"14.

A pintura era, portanto, considerada um discurso pictórico; estático, construído matematicamente, do mesmo modo como o discurso do orador era construído parte a parte. Haveria, num como no outro, uma preocupação com cada elemento da estrutura retórica: inventio (assunto), dispositio (encadeamento), elocutio (estilo), memoria (memória) e actio (realização). Também por isso, a formação da escola de belas-artes erigia-se sob o primado do desenho, não havendo curso de pintura propriamente dito. O pintor precisava ser antes um desenhista do que um colorista - e dominar a perspectiva clássica, à época, era dominar o desenho; saber trabalhar com proporção e distribuição na tela. Por esse ângulo, o ato de pintar deveria ser realizado de tal maneira que o toque do pintor - materialização de seu trabalho no quadro - fosse imperceptível.

Assim, um trabalho de pintura bem realizado segundo a lógica da tradição - de sua busca pelo ideal -, seria um trabalho com ares de perfeição, isto é, um trabalho que produzisse a impressão de não ter sido feito por mão humana. Ao final do processo de pintura, as telas eram envernizadas para que os resíduos restantes do contato entre pincel e tela fossem ocultados; era preciso, em outras palavras, fazer melhor do que a realidade. Trata-se, com efeito, de uma ideia de atemporalidade em pintura, a partir da qual o que está em jogo não é o instante, mas o eterno.

Ora, o impressionismo viria repensar ou colocar em xeque cada um desses pilares. No texto em questão neste trabalho, as linhas de força que, segundo Marchal, Mallarmé constata na pintura desses artistas (recordemo-las: ar livre, simplificação, perspectiva e descondicionamento do olhar) ilustram de forma precisa essa mudança de paradigma. É dela que se ocupam as linhas a seguir.

\section{O alr livire}

Uma das primeiras revoluções da pintura no XIX consiste na alteração da maneira como os ateliês eram iluminados. Se antes eles se voltavam para o norte, de modo a impedir que a luminosidade penetrasse diretamente, produzindo uma variação constante ao longo do dia, agora passavam a ser voltados para o sul, a fim de estimular o processo de pintura a acompanhar as mudanças da luz ao longo do dia, tornando possível o registro da luminosidade. Tal ideia provinha de casos significativos na história da arte, como o de Rembrandt (1606-1669), por exemplo, cuja reputação de "pintor da luz" dá já o tom da empreitada.

\footnotetext{
14 "La composition classique arrange les objets comme s'ils étaient fixes et statiques, peut-être dans l'intention de donner l'impression d'un temps éternel et stable."
} 


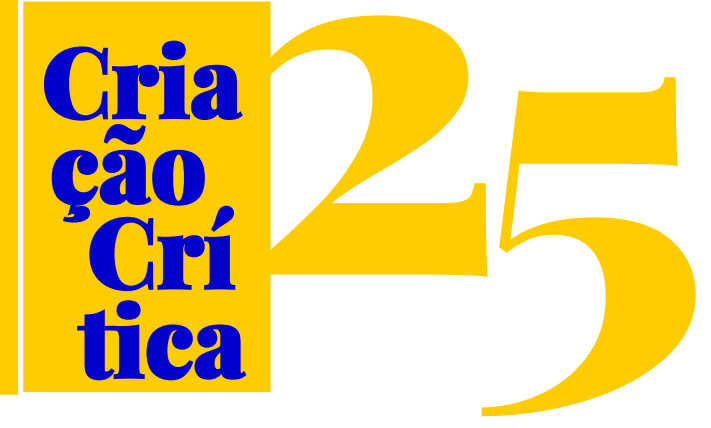

De fato, a captura do instante, nos quadros impressionistas, não funciona sem "o encanto de um limite meramente fantasioso", o qual fixa esse instante, sem nem por isso fazer com que ele seja destituído da qualidade de seu movimento; a impressão deve ser sempre a de algo cambiante, que "palpita com movimento, luz e vida"23 (MALLARMÉ, 2003 [1876], p. 456). Como não se trata mais de pintar a perfeição e a eternidade, as marcas do pincel, aparentes na tela, põem fim à invisibilidade do pintor, valorizada na tradição. O aparente inacabamento, resumido na palavra simplificação realça a "harmonia das cores e a impressão produzida por essa harmonia"24 (SHIGEMITSU, 2001, p. 25), e é sinal, precisamente, de que o quadro foi feito por mãos humanas, com todas as suas imperfeições. Nesse sentido, a noção de belo não responde mais a algo da ordem do perene, do celestial ou do imutável; ao contrário, como se vê no Olympia de Manet, comentado por Mallarmé em "The Impressionists", o nu não é idealizado nem sublime. Trata-se de um nu real demais, no qual fica explícita a posição de cortesã ocupada pela figura na tela, jamais antes retratada com tamanha crueza.

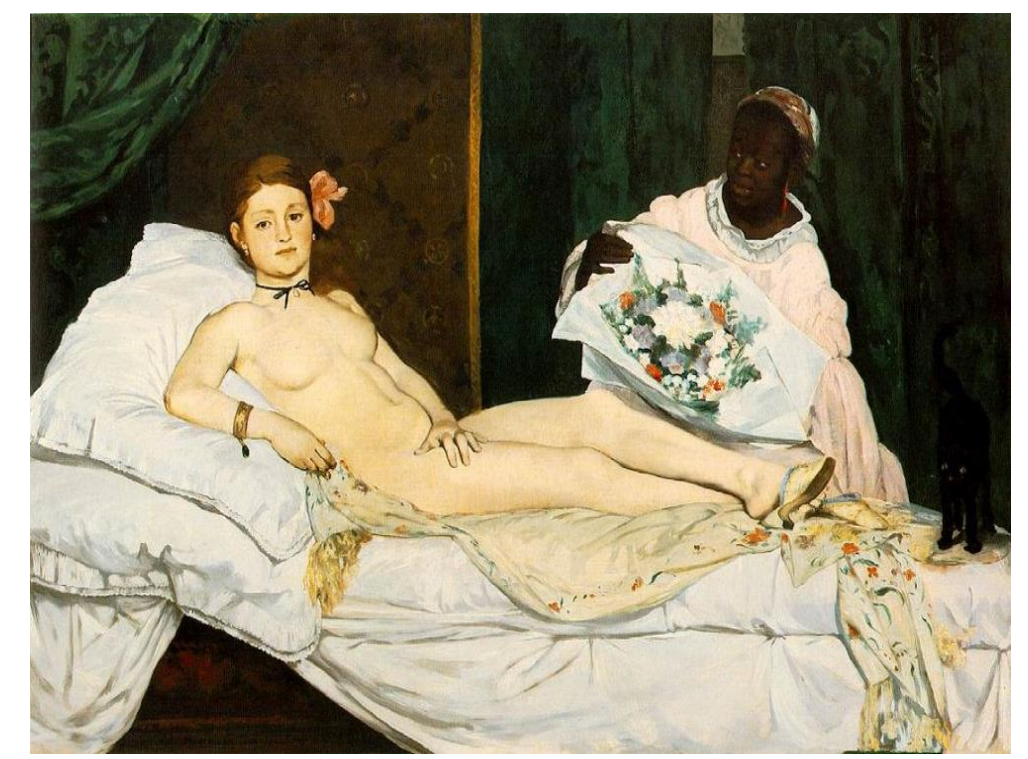

Figura 2 - Olympia, 1863, óleo sobre tela, 130,5 x 190 cm, Musée d'Orsay, Paris

Essa simplificação, patente tanto nas figuras como nos ambientes, e alcançada na tela pelo auxílio de cores claras, aplicadas parcial ou sucessivamente, contrapõe-se ao aspecto rebuscado, artificial da moldura, causando a impressão de que, ao ser transportado pela contemplação de alguma cena natural, o observador não pode se desprender completamente do fato de estar diante de um quadro.

\footnotetext{
23 "palpitates with movement, light, and life".

24 "Quant à la simplification, elle signifie que le peintre attaché essentiellement de l'importance à l'harmonie des couleurs et à l'impression produite par cette harmonie."
} 


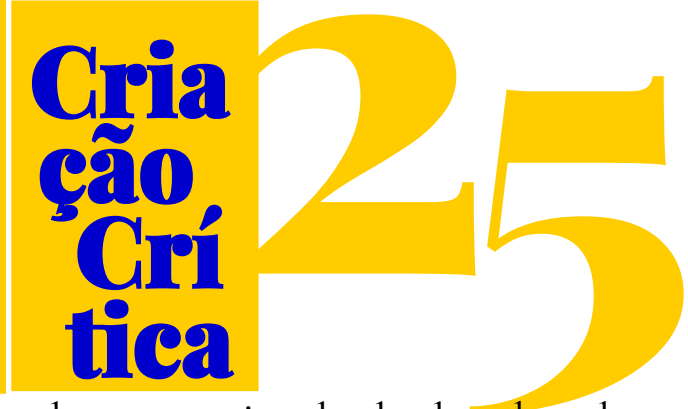

A preocupação deixa de ser, dessa maneira, direcionada a um primado do desenho; ela passa a se ligar, primeiramente, ao uso da cor sob a influência da luz natural e da atmosfera que incidem sobre pessoas e objetos. Como descrito em "The Impressionists", tal incidência parece roubar das figuras retratadas "alguma substância e solidez, ao passo que os contornos, consumidos pelo sol encoberto e desgastados pelo espaço, tremem, derretem-se e evaporam na atmosfera ao redor, a qual extrai realidade das figuras, mesmo que pareça fazê-lo apenas para preservar-lhes o aspecto de verdade"36 (MALLARMÉ, 2003 [1876], p. 456). Ora, esse talvez seja o melhor exemplo do questionamento que os impressionistas esboçam quanto à estrutura retórica clássica.

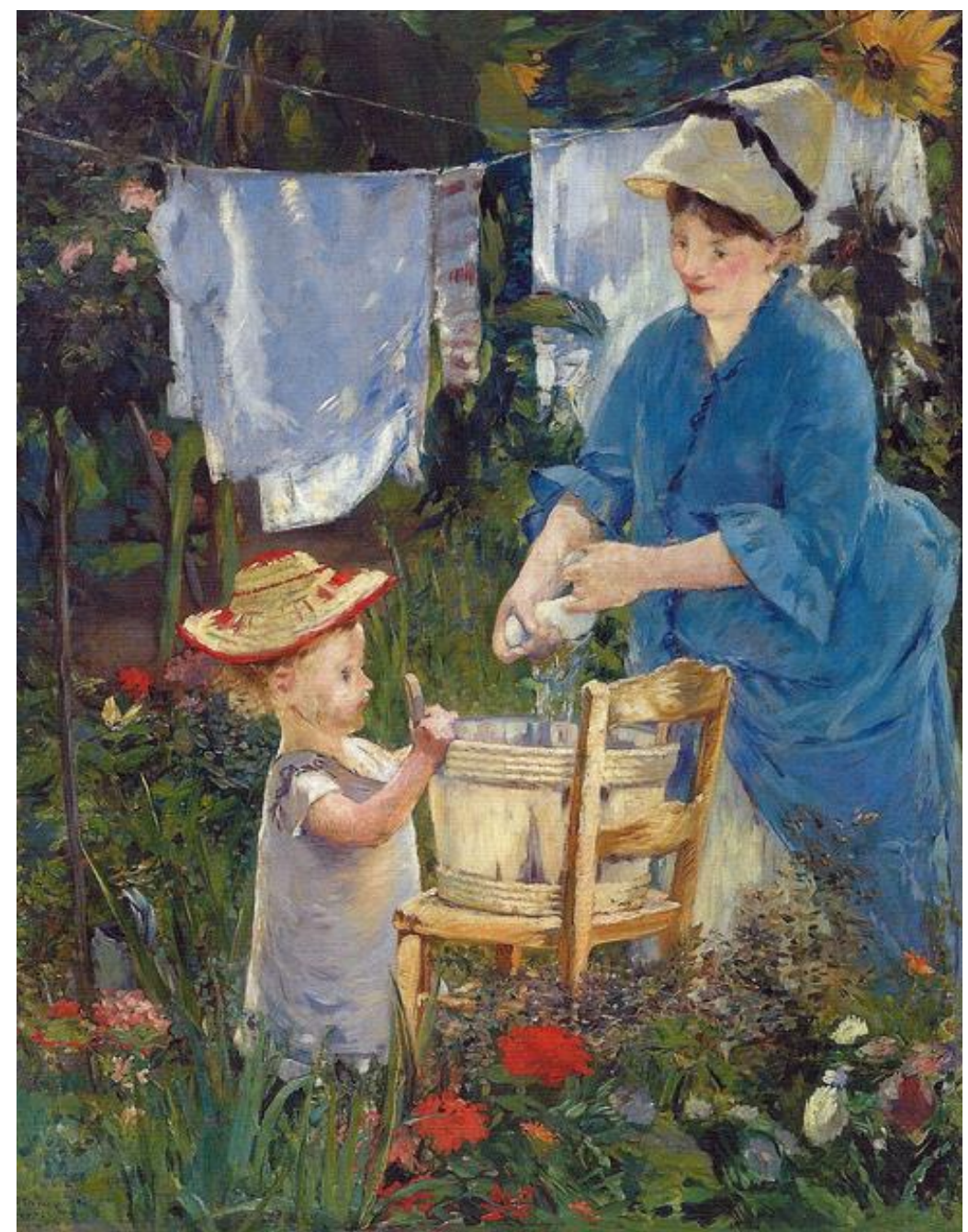

Figura 3 - Le linge, 1875, óleo sobre tela, 145 x 115 cm, Barnes Foundation, Philadelphia

É claro que tanto as telas desses pintores como os escritos de Mallarmé estão calcados num pensamento retórico à maneira dos antigos, e por isso operam, de uma forma ou de outra, por meio de um certo uso da estrutura retórica clássica. Mas isso não os impede de apresentar divergências a

\footnotetext{
36 "some of their substance and solidity; whilst their contours, consumed by the hidden sun and wasted by space, tremble, melt, and evaporate into the surrounding atmosphere, which plunders reality from the figures, yet seems to do so in order to preserve their truthful aspect".
} 


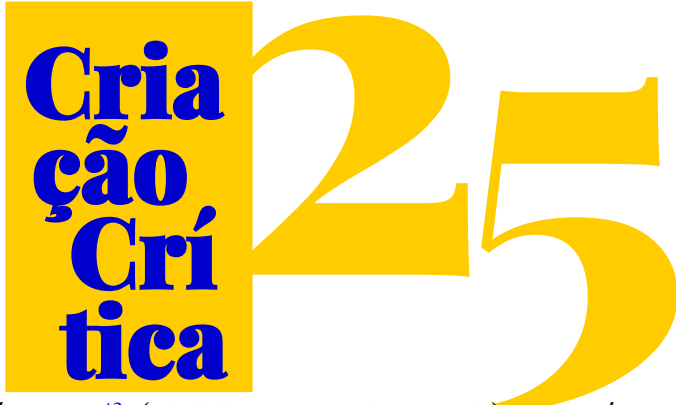

virtudes ao mesmo tempo unificadoras e transcendentais da língua"42 (ETTLIN, 2017, p. 17), isto é, dito de outra forma, para com as ficções às quais atribuímos, todos nós, status de verdade.

É dessa forma, pois, que uma última tentativa comum entre a pintura impressionista e a poética mallarmeana - tanto dos anos 1870, pelo exemplo de "Don du poëme", como dos anos 1890, conforme se identifica em diversos momentos de La Musique et les Lettres - é a de descondicionar o olhar.

\section{O descondicionamento dlo ollhar}

Em La Musique et les Lettres, essa ideia de ficção - cuja desmontagem ímpia o poeta se propõe a fazer - pode ser entendida justamente como um problema de discurso, e talvez principalmente, do discurso que tem por pretensão o convencimento. Trata-se, portanto, de um problema da ordem das letras - daí Mallarmé mencionar a desmontagem do mecanismo literário ${ }^{43}$-, o qual, todavia, dificilmente poderia ser solucionado, e que o seria menos ainda com a explicação essencialmente retórica do poeta na conferência de Oxford e Cambridge - uma desmontagem ímpia, portanto; cética, para dizer tudo.

Parece ser com isso em vista que Marchal resume (1997, p. 293) a problemática de La Musique et les Lettres nos seguintes termos: um discurso para ser lido, o qual aparece, então, como metadiscurso,

um discurso que diz, a seu modo, a impossibilidade do discurso, a inadequação do tratamento retórico, e que inventa, em suma, uma retórica, metafórica e reflexiva, na qual a digressão - a divagação - se sobrepõe à argumentação. Esse discurso não visa convencer, isto é, colocar para funcionar os mecanismos tradicionais do crédito, mas suscitar, ao contrário, uma prática da leitura que consiste em desconstruir esses mecanismos do crédito... ${ }^{44}$

Ora, tornando a pensar na actio contestada pela pintura impressionista, a perspectiva, quando ciência completa e artificialmente clássica que transforma nossos olhos em joguetes de uma educação civilizada, contribuiria para que essas ficções, por meio da convenção, passassem despercebidas. Por essa lógica, descondicionar o olhar demasiado habituado às convenções - através, por exemplo, do trabalho com uma perspectiva bidimensional - aparece como uma questão para a então nova escola.

\footnotetext{
42 "des croyances dont nos communautés ont besoin - la croyance en l'idée, en l'existence de la vérité, en celle de l'absolu, en les vertus à la fois fédératrices et transcendantales de la langue".

${ }^{43}$ Ettlin (2017, p. 17) talvez ajude a melhor compreender a questão: "graças à literatura, a ideia, a verdade, o absoluto, os valores cultural e transcendental da língua passam a existir, quando neles se crê, se a eles é dada uma forma e se se começa a agir ou a interagir de acordo com eles." ["grâce à la littérature, l'idée, la vérité, l'absolu, les valeurs culturelle et transcendantale de la langue existent, quand on y croit, qu'on leur donne forme e qu'on se met à agir ou interagir en conséquence."]

44 "Ce discours à lire apparaît alors comme un métadiscours, un discours qui dit à sa façon l'impossibilité du discours, l'inadéquation du traitement rhétorique, et qui invente en somme une autre rhétorique, métaphorique et réflexive, où la digression - la divagation - prend le pas sur l'argumentation. Ce discours-là ne vise plus à convaincre, c'est-à-dire à faire fonctionner les mécanismes traditionnels du crédit, mais à susciter au contraire une pratique de lecture qui consiste à déconstruire ces mécanismes du crédit..."
} 


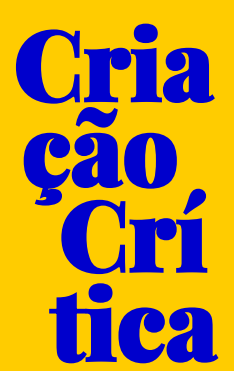

Esse descondicionamento que Mallarmé identifica mais pontualmente na prática de Manet apresenta-se como um impulso de se "ignorar tudo o que foi feito em arte por outros, e tirar de sua própria consciência efeitos de simplificação"45 (MALLARMÉ, 2003 [1876], p. 459). Não se trata, portanto, de renegar tudo o que veio anteriormente - de acordo com Mallarmé, Manet era "visitante nas principais galerias francesas e estrangeiras, e um erudito estudioso de pintura"46 (MALLARMÉ, 2003 [1876], p. 459) -, mas de desconsiderar intencionalmente com vistas a uma problematização, a uma atitude crítica.

Mallarmé entende que, pela proposta impressionista, "cada trabalho deve ser uma nova criação do espírito"47 (MALLARMÉ, 2003 [1876], p. 448):

A mão, é verdade, conservará alguns dos segredos de manipulação adquiridos, mas o olho deve esquecer tudo aquilo que já viu e aprender novamente a lição diante dele. Deve abstrair-se da memória, enxergando só aquilo que vê, e como se pela primeira vez; ao passo que a mão deve tornar-se uma abstração impessoal guiada apenas pelo impulso, alheia a todo ardil prévio. ${ }^{48}$ (MALLARMÉ, 2003 [1876], p. 448)

Assim, Manet preconizaria uma fuga quanto às convenções da pintura, uma vez que embora suas telas sejam, em geral, em grande formato, seus assuntos de predileção não são

emprestados das Escrituras, da mitologia ou da História, nem de determinado personagem ilustre, isto é, assuntos impregnados de eternidade ou de majestade, que haviam feito a delícia de muitos pintores antes dele, incluindo os românticos, seus predecessores imediatos: os assuntos de Manet são as pessoas, uma multidão, uma paisagem ou um espetáculo visto ordinariamente na vida cotidiana. ${ }^{49}$ (SHIGEMITSU, 2007, p. 25)

\footnotetext{
45 "to ignore all that has been done in art by others, and draws from his own inner consciousness all his effects of simplification".

46 "visitor to the principal galleries both French and foreign, and an erudite student of painting".

47 "Each work should be a new creation of the mind".

48 "The hand, it is true, will conserve some of its acquired secrets of manipulation, but the eye should forget all else it has seen, and learn anew from the lesson before it. It should abstract itself from memory, seeing only that which it looks upon, and that as for the first time; and the hand should become an impersonal abstraction guided only by the will, oblivious of all previous cunning".

49 "D'abord, les sujets préférés de Manet ne sont plus des sujets empruntés aux Écritures, à la mythologie, ou à l'Histoire, ni à certains grands personnages, autrement dit, des sujets empreints d'éternité ou de majesté qui ont fait les délices de bien des peintres avant lui, y compris les romantiques, ses prédécesseurs immédiats : les sujets de Manet sont des gens, une foule, un paysage ou un spectacle qu'on voit ordinairement dans la vie quotidienne."
} 


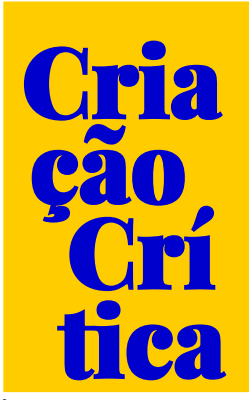

apenas os tivéssemos visto pela primeira vez"50 (MALLARMÉ, 2003 [1876], p. 466). Um problema matemático, pensando em Edgar Poe; porém, guiado apenas pelo impulso, alheio a todo ardil prévio. E nesse sentido, precisamente, a proposição de um novo mecanismo retórico - metafórico e reflexivo -, o qual visava suscitar uma prática da leitura movida pelo ímpeto de desconstruir os mecanismos da convenção, na esteira do que sugere Marchal, como foi mostrado ainda há pouco.

\section{Considerações fiinais}

As linhas de força comentadas nas páginas anteriores ecoam, em última instância, uma nova sensibilidade que emergia naquele fim de século. Elas descrevem o lado pictórico da "crise inesperada" sobre a qual se debruça "The Impressionists", e clarificam, nesse sentido, a própria pesquisa poética de Mallarmé (ILLOUZ, 2016, p. 201).

Como os exemplos utilizados puderam ilustrar, o objetivo deste trabalho foi apontar o modo como os comentários que Mallarmé elabora sobre a pintura impressionista, especialmente a produzida por Manet, colocam-se em diálogo com certas operações poéticas presentes tanto em sua obra de juventude, pelo exemplo de "Don du poëme", como nos momentos mais tardios de seus escritos, aqui pensados por meio de trechos extraídos de La Musique et les Lettres.

Mais do que isso, esse estudo analítico procurou observar mais de perto uma das relações maiores entre a pintura e a poesia em fins do século XIX francês, a partir de reflexões presentes num artigo pouquíssimo conhecido de Mallarmé - e menos ainda aqui no Brasil -, o qual, não obstante, mostra-se, também pelas razões supracitadas, fundamenta ${ }^{51}$.

\section{Referềncias}

BAUDELAIRE, C. CEuvres Complètes. Édition de Y.-G. le Dantec. Paris: Gallimard, 1954.

COHN, R. G. Mallarmé's Prose Poems, A Critical Study. Cambridge: Cambridge Univ. Press: 1981.

DURAND, P. Crises. Mallarmé via Manet (De «The impressionists and Édouard Manet» à «Crise de vers»). Leuven, Peeters: Vrin, 1998.

ETTLIN, A. Le double discours de Mallarmé: une initiation à la fiction. Genève: Éditions d'Ithaque, 2017.

FUMAROLI, M. Trois institutions littéraires. Paris: Gallimard, 1994.

\footnotetext{
50 "to make us understand when looking on the most accustomed objects the delight that we should experience could we but see them for the first time.".

${ }^{51}$ Trata-se, com efeito, de uma primeira aproximação de "The Impressionists" em formato de artigo, mas que faz parte de um projeto maior de estudo desse texto. Oportunamente, serão apresentadas outras aproximações desse trabalho mallarmeano de 1876 .
} 


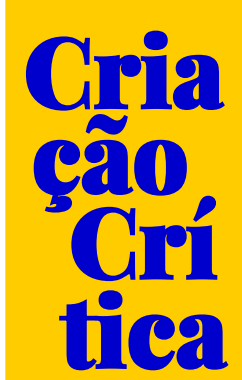

HARRIS, J. C. "A little-known essay on Manet by Stéphane Mallarmé". In: The Art Bulletin, v. XLVI, n. 4, dez, 1964.

HORÁCIO. Epistola ad pisones. Ed. bilíngue. Organização de B. Maciel, D. Monteiro, J. Avelar e S. Bianchet. Belo Horizonte: FALE/UFMG, 2013.

ILLOUZ, J.-N. "Les Impressionnistes et Stéphane Mallarmé". In: Revista Non Plus (São Paulo), ano 5 , n 10, jul.-dez. 2016. Disponível em: <http://www.revistas.usp.br/nonplus/article/view/130967>. Acesso em: 13 de maio de 2018

MALLARMÉ, S. Écrits sur l'art. Édition de M. Draguet. Paris: GF-Flammarion, 2015.

Cuvres Complètes. Édition de B. Marchal. vol. 1 et 2. Paris: Gallimard, Bibliothèque de la Pléiade, 1998 et 2003.

MARCHAL, B. "Mallarmé critique d'art?". In: Revue d'histoire littéraire de la France (Paris), v. 111, Presses Universitaires de France, 2011/2, p. 333-340. Disponível em: <https://www.cairn.info/revued-histoire-litteraire-de-la-france-2011-2-page-333.htm>. Acesso em: 13 de maio de 2018.

"La Musique et les Lettres' de Mallarmé". In: MARCHAL, Bertrand; STEINMETZ, J. -L. (dir.)Mallarmé ou l'obscurité lumineuse. Paris: Hermann, 2014. [1997]

MESCHONNIC, H. "Oralité, clarté de Mallarmé". In: Europe (Stéphane Mallarmé), p. 825-826, 1998.

POE, E. The works of Edgar Allan Poe III. Edited by J. H. Ingram. London: A. \& C. BLACK, 1899. [1874-1875]

SHIGEMITSU, M. "Ce que Mallarmé voit dans la peinture de Manet", Bul. Hijiyama University, № 14, 2007. Disponível em: <http://harp.lib.hiroshima-u.ac.jp/hijiyamau/file/4859/20140122093335/hjg1403.pdfs

STROPARO, S. M. Cartas de Mallarmé: leitura, crítica e tradução. 2012. 288 f. Tese de Doutorado Centro de Comunicação e Expressão, Universidade Federal de Santa Catarina. Florianópolis. Disponível em: <https://repositorio.ufsc.br/xmlui/handle/123456789/96426>

VALÉRY, P. CEuvres Complètes. Notes par J. Hytier. Paris: Gallimard, 1957. 